\title{
DIGNIDADE, RECONHECIMENTO E CONSTITUIÇÃO: ENTRE KANT E HEGEL
}

Dignity, recognition and Constitution: Between Kant and Hegel

Thadeu Weber*

Resumo: $\mathrm{O}$ texto pretende evidenciar aspectos da atualidade do pensamento de Kant e Hegel. Além de destacar uma certa complementaridade entre eles, indica e comenta suas contribuições ao debate de temas importantes da Ética e da Filosofia Política Contemporâneas, tais como: dignidade, autonomia, fundamentação ética da Constituição, reconhecimento recíproco e liberdade.

Palavras-chave: Liberdade. Dignidade. Autonomia. Constituição. Reconhecimento.

Abstract: This paper points out to some aspects of the current relevance of Kant and Hegel's thought. In addition to highlighting a certain complementarity between them, it identifies and comments on their contributions to the debate on important themes of contemporary ethics and political philosophy, such as dignity, autonomy, the ethical foundations of the Constitution, reciprocal recognition and liberty.

Keywords: Liberty. Dignity. Autonomy. Constitution. Recognition.

* Doutor em Filosofia, Professor da PUCRS, dos Programas de Pós-Graduação em Filosofia e em Direito. Artigo recebido em 03/04/2019 e aprovado para publicação em 04/12/2019. 


\title{
1. Introdução: aspectos complementares entre Kant e
} Hegel

\begin{abstract}
inegável contribuição do pensamento de Kant e Hegel à Filosofia Política Contemporânea pode ser medida pelas suas influências e 1 repercussões. Em referência a Kant, temos uma avaliação da competência da razão, dessa forma apontando o alcance e seus limites. Com isso, tanto do ponto de vista teórico quanto prático, o estabelecimento do âmbito e dos limites da razão foi, sem dúvida, o maior legado. No tocante a Hegel, decorre uma esquerda e uma direita, suscitando discussões relevantes até nossos dias.
\end{abstract}

É por demais conhecida a crítica de Hegel ao formalismo da filosofia moral kantiana, caracterizando-a como uma "indeterminação abstrata"1. Desse diálogo muito se valeram os debates entre liberais e comunitaristas, amplamente conhecidos na Filosofia Política Contemporânea. Não é objeto desse artigo entrar nessas controvérsias, mas apenas apontar uma relação complementar entre esses dois gigantes do idealismo alemão².

Encontramos em Kant, através de uma ética do dever pelo dever, uma ênfase na ética das intenções. Dessa forma, para preservar a autonomia da vontade não pode ela ser determinada pelo cálculo de possíveis consequências. A importância de se considerar as intenções dos sujeitos agentes na emissão de um juízo moral é inegável, porém insuficiente, pois envolve apenas as condições de responsabilidade subjetiva. Todavia, em Hegel, encontramos uma crítica consequencialista da filosofia moral kantiana. Ou melhor, além dos propósitos e intenções, enquanto fundamentação subjetiva da vontade moral, necessita-se acrescentar uma avaliação dos meios usados, bem como das consequências e das repercussões das ações humanas. Com a eticidade, Hegel vai além da moralidade, enquanto esta trata apenas das condições da responsabilidade subjetiva e aquela da concretização da vontade livre nas instituições sociais. A ideia de reconhecimento recíproco passa a ter um papel legitimador dos contratos e acordos das mediações sociais. Mas como se dá a passagem da moralidade para a eticidade? Como partir da fundamentação subjetiva da vontade livre para as suas determinações objetivas?

A complementaridade dos dois autores pode ser claramente estabelecida: De Kant extraímos as condições da responsabilidade subjetiva e de Hegel apreendemos a necessidade de avaliar o desdobramento objetivo da vontade livre nas instituições sociais. Importam, também, as consequências e

\footnotetext{
${ }^{1}$ Sobre a crítica de Hegel ao formalismo da moral kantiana, ver: Weber, Thadeu. Ética e Filosofia Política. Porto Alegre: EDIPUCRS, 2009.

${ }^{2}$ Um exaustivo estudo sobre liberalismo e comunitarismo é feito por Rainer Forst, em Contextos da Justiça. São Paulo: Boitempo, 2010.
} 
as repercussões. Com isso, se enfraquece o apriorismo da moral kantiana, em nome da consideração do contexto da eticidade hegeliana. Os conceitos de liberdade negativa e optativa são complementados com o de liberdade social, isto é, a liberdade mediada e efetivada nas instituições da eticidade. Honneth, com sua "reatualização da Filosofia do Direito de Hegel", dá muito destaque a esse terceiro conceito de liberdade, exatamente por acreditar estarem aí as bases de uma filosofia social.

Desfavoravelmente à separação entre ética e direito em Kant, Hegel contrapõe a estreita vinculação entre direito, moralidade e eticidade. Poderíamos dizer que Hegel juntou o que Kant separou. Esta separação, no entanto, não foi gratuita. Exerceu enorme influência nas doutrinas liberais na segunda metade do século XX. A ideia de liberdade negativa e de uma neutralidade ética do direito são amplamente endossadas por aquelas ${ }^{3}$. Uma das razões fundamentais desse endosso é o estabelecimento de uma garantia dos direitos e liberdades individuais e sociais. Com isso, o direito torna-se, efetivamente, uma "capa protetora da pessoa do direito" 4 . Para isso a distinção entre leis éticas e leis jurídicas (espécie) a partir das leis morais (gênero) feita por Kant em A Metafísica dos Costumes, é fundamental. As leis morais é que se dividem em jurídicas e éticas. $\mathrm{O}$ que as distingue é a sua diferente motivação. O Direito, portanto, tem base moral, mas não ética. Forst, em parte, se apropria dessa distinção quando diferencia quatro contextos da justiça: o ético, o jurídico, o político e o moral ${ }^{5}$. O objetivo dele é esclarecer uma das teses centrais do liberalismo: a neutralidade ética do direito.

Por outro lado, com a fundamentação ética do político, Hegel lança as bases do comunitarismo: direito, ética e moral não podem ser separados. As conquistas da História e a consideração do contexto enfraquecem o apriorismo da filosofia prática de Kant e destacam a insuficiência de dois modelos de liberdade: a negativa e a optativa, amplamente discutidas na Filosofia do Direito. O "espírito do povo" (sua cultura, sua história, suas origens e seus costumes) deve ser considerado como o fundamento ético da Constituição do Estado. De modo consequente, N. Bobbio tem razão ao enfatizar a concepção ético-política da Constituição como base de uma concepção positiva da mesma, esta defendida por Kant e com forte influência no positivismo jurídico ${ }^{6}$.

É oportuno enfatizar que a concepção de pessoa é, fundamentalmente, a mesma em ambos os autores: a pessoa de direito é ao mesmo tempo sujeito de direitos. Quer dizer, a pessoa com capacidade legal tem competência para a titularidade de direitos. A diferença está nas formas de concretização

${ }^{3}$ Cf. FORST, R. Contextos da Justiça. São Paulo: Boitempo, 2010, p. 54.

${ }^{4}$ FORST, R. Contextos da Justiça. São Paulo: Boitempo, 2010, p. 90.

${ }^{5}$ Cf. FORST, R. Contextos da justiça. São Paulo: Boitempo, 2010, p. 13.

${ }^{6}$ BOBBIO, N. Estudos sobre Hegel. São Paulo: Brasiliense, 1991, p. 104. 
dessa capacidade. Em Hegel, ela se efetiva através das figuras que constituem o movimento dialético da Filosofia do Direito, isto é, da concretização da ideia da liberdade. $\mathrm{O}$ direito abstrato trata das formas mais imediatas da realização dessa capacidade jurídica da pessoa; a moralidade investiga as condições da responsabilidade subjetiva da vontade livre e a eticidade seu desdobramento objetivo nas instituições sociais. É nestas que os direitos fundamentais da pessoa de direito adquirem plena efetividade. Em Kant, a racionalidade e a razoabilidade indicam as condições pressupostas para possibilitar a autolegislação da razão. A propósito, Rawls destaca essas "qualidades morais" da pessoa de direito, solidificando uma concepção normativa e política e não mais metafísica, como condição para o exercício da cidadania, isto é, a convivência numa sociedade cooperativa.

\section{Autonomia e dignidade humana.}

O princípio da dignidade humana adquiriu no século XX o status de marco teórico dos grandes acordos políticos nacionais e internacionais. É um dos fundamentos da Constituição brasileira de 1988 e da maioria dos Estados Democráticos de Direito. O consentimento livre e informado é requisito básico de qualquer pesquisa com seres humanos e da relação médico/paciente. $\mathrm{O}$ princípio da autonomia é o fundamento da democracia, das ações eticamente corretas e do Estado Democrático de Direito. Nesses quesitos, somos profundamente devedores de Kant e Hegel. Do mesmo modo, encontramos neles a explicitação do conteúdo desses princípios e de sua justificação. Quanto à influência e referência a esses temas, Kant foi decisivo para o fortalecimento das bases do liberalismo. Com a distinção entre direito, moralidade e eticidade, como formas de efetivação da ideia da liberdade, na Filosofia do Direito, Hegel apresenta uma fundamentação ética da Constituição do Estado e lança as bases do comunitarismo. A distinção entre a fundamentação subjetiva da vontade livre (moralidade) e a demonstração da necessidade de seu desdobramento objetivo nas instituições sociais (eticidade) representa uma enorme contribuição para os debates em torno do tema da responsabilidade, tanto subjetiva quanto objetiva, principalmente no que diz respeito às consequências e repercussões das ações humanas.

Autonomia e dignidade são a base dos argumentos e das relações ético-políticas. Em torno deles giram os princípios norteadores do exercício do poder político e da conduta eticamente correta. Se nos concentrarmos mais especificamente na filosofia moral, encontramos nas formulações do imperativo categórico kantiano esses dois conceitos devidamente explicitados. $\mathrm{Na}$ segunda formulação encontramos o conceito de dignidade humana como marco teórico fundamental. Tratar a humanidade, "tanto na sua pessoa como na pessoa de qualquer outro, sempre e simultaneamente, como fim 
e nunca simplesmente como meio"7 indica a razão elementar do respeito à dignidade: a capacidade de consentimento do ser humano. Aliás, tratar alguém simplesmente como meio significa impedir o seu consentimento. Exemplificando, podemos tratar alguém como meio desde que ele saiba de minha intenção e concorde com essa ação. Consequentemente, não posso usar o homem na minha pessoa simplesmente como meio porque ele não tem preço e, sim, dignidade. Ele é um fim em si mesmo.

A atualidade de Kant e Hegel não está somente na sua concepção metafísica de pessoa e dignidade, mas também e principalmente na influência que causaram na positivação e sua concretização na forma de direitos fundamentais, sobretudo nas constituições democráticas do século XX e XXI. Na Filosofia do Direito de Hegel, a dignidade está expressamente vinculada à ideia de liberdade como princípio orientador e fundamentador das estruturas jurídicas e sociais. Tomando como ponto de partida a capacidade jurídica da pessoa, o conteúdo da dignidade é explicitado mediante as diversas figuras da concretização dessa capacidade. A proteção da dignidade requer a garantia do exercício dessa capacidade. O conceito de liberdade em jogo é comum aos dois autores: a autodeterminação da vontade.

Se ligarmos essa concepção de dignidade com a terceira formulação do imperativo categórico, temos elaborada a principal tese da filosofia prática kantiana: a autonomia é o fundamento da dignidade humana. A capacidade da autolegislação da razão, ou seja, a capacidade de construir a lei a qual se submete é que confere dignidade. Tornar-se legislador para a comunidade moral da qual se faz parte é a essência da autonomia moral. Afirma Rawls, interpretando Kant: "o fundamento da dignidade é a capacidade de fazer a lei universal e de agir segundo o princípio da autonomia"8. A função autolegisladora da razão é o que confere dignidade à pessoa humana. Com isso, Kant nos ensinou que não podemos contentar-nos em seguir ou obedecer a regras, precisamos de uma justificação para elas. Ora, a autonomia é a faculdade dos seres racionais de agir de acordo com princípios, demonstrando controle sobre as paixões 9 . O imperativo categórico, com suas diferentes formulações, assume esse papel. Ele é um critério de construção e justificação de normas morais ${ }^{10}$. Essa capacidade de justificação das ações é que nos confere dignidade.

\footnotetext{
${ }^{7}$ KANT, I. Grundlegung zur Metaphysik der Sitten. Frankfurt am Main: Suhrkamp, 1974, BA67. ${ }^{8}$ RAWLS, J. História da Filosofia Moral. São Paulo: Martins Fontes, 2005, p. 241.

${ }^{9}$ Cf. PATON, H. J. The Categorical Imperative. Philadelphia: UPP, 1971, p. 212.

${ }^{10}$ Uma interpretação construtivista do imperativo categórico kantiano é feita por Rawls (História da Filosofia Moral, 2005, p. 192). Se o entendermos como um procedimento então podemos considerá-lo como uma fórmula para a elaboração de normas de ação. O imperativo categórico, tal como a posição original de Rawls, não é construído. Ambos são simplesmente estipulados. O que é construído através desse procedimento são regras morais (conteúdo) (Kant) e princípios de justiça (Rawls). É claro que isso supõe a distinção entre lei moral como ideia da razão e imperativo categórico como procedimento, onde este é a aplicação daquela (cf. Rawls, 2005, p. 192).
} 
Observa-se que a autonomia e a dignidade são qualidades intrínsecas da pessoa humana e, portanto, a base da ação com mérito moral e da vivência democrática. $\mathrm{O}$ fato de participarmos da construção das leis é o que legitima sua validade. O consentimento é o que dá legitimidade a qualquer deliberação e juízo moral. Essa tese norteia, hoje, por exemplo, as análises e decisões dos comitês de ética em pesquisa com seres humanos. Também conduz os sistemas legislativos de todo Estado Democrático de Direito. Kant e Hegel se ocupam expressamente da justificação da autonomia e do livre consentimento: Kant, centrado no indivíduo, Hegel, nas mediações sociais.

Sob o mesmo ponto de vista, Tugendhat resume bem o significado do imperativo categórico para os nossos dias. O imperativo "nunca use o ser humano simplesmente como meio" resulta no mandamento "não instrumentalizes ninguém" e positivamente, afirma: "respeita-o como sujeito de direito"11. Assim, que todo cidadão seja reconhecido como sujeito de direitos é a base das democracias contemporâneas e orienta as teorias da justiça que apostam na igualdade de todos perante a lei, igualmente respeitando as diferenças. É por isso que, já, Hegel toma como ponto de partida da efetivação da ideia da liberdade a noção de pessoa de direito, ou melhor, a capacidade jurídica da pessoa enquanto portadora de direitos.

A atribuição de dignidade unicamente às pessoas humanas é objeto de muitas controvérsias ${ }^{12}$. Deveríamos incluir os animais a fim de resguardar seus direitos? E os vegetais? Contudo, se tiverem dignidade podemos usá-los simplesmente como meios? E o consentimento? Será o conceito kantiano de dignidade muito restritivo?

Kant certamente reserva a denominação dignidade aos seres racionais. Nesse sentido, trata-se de um antropocentrismo. Mas não é exatamente aí que está seu mérito? Se ampliarmos demasiadamente o conceito de dignidade, acabamos esvaziando-o ou enfraquecendo seu conteúdo. Se tudo tem dignidade, nada mais é digno. Ou será que teríamos que admitir graus hierárquicos de dignidade? Certamente não precisamos atribuir dignidade aos animais para respeitá-los. Revelamos nossa identidade (personalidade) pela maneira como os tratamos. Restringir a dignidade ao homem indica e enobrece qualidades específicas dos seres racionais, tais como a sua capacidade de ter bom caráter, de ter boa vontade e de ter personalidade moral. É por isso que não se pode instrumentalizá-lo. Ele é sujeito de direitos, mesmo que não possa efetivá-los. É o que queremos significar com o ser "pessoa de direito". Do ponto de vista ético, jurídi-

\footnotetext{
${ }^{11}$ TUGENDHAT, E. Lições de Ética. Petrópolis: Vozes, 1997, p. 155.

${ }^{12}$ I. Sarlet, por exemplo, refere-se a um "excessivo antropocentrismo" dessa concepção de dignidade kantiana (ver, Dignidade da pessoa humana e direitos fundamentais, 2002, p. 35). Também Dimensões da Dignidade, 2009, primeiro capítulo.
} 
co e político essa concepção antropológica é de indiscutível relevância e atualidade, ainda que seja uma concepção metafísica. Rawls vai entendê-la como concepção normativa, pressuposta na sua concepção política de justiça. As "qualidades morais" a ela atribuídas e exigidas, pelo menos em grau mínimo necessário para o pleno exercício da cidadania, são as mesmas: a racionalidade e a razoabilidade.

A tese kantiana de que a autonomia é o fundamento da dignidade permite colocar uma questão fundamental: os que não têm condições de exercer a autonomia (doentes mentais, presos, etc.) perdem a dignidade? Certamente a autonomia não é o único fundamento da dignidade. Ela tem limites. Em Kant não existe, por exemplo, o direito ao suicídio. A dignidade é constitutiva da própria concepção de pessoa como fim em si mesma. Portanto, não ter condições de exercício da autonomia não significa não ter dignidade. Isso significa, para Sarlet, que a autonomia, em sentido kantiano, deve ser considerada como autonomia potencial ${ }^{13}$

Além do mais, é preciso que se reconheça e enfatize a importância da terceira formulação do imperativo categórico, a da autonomia, para as teorias éticas posteriores. Com a legislação para um "reino dos fins", Kant antecipa formulações que consagram as teses de grandes mestres da filosofia moral e política contemporânea: a "comunidade ideal de comunicação" de Apel e o "mundo social ajustado" de Rawls, entre outros ${ }^{14}$. Outrossim, o "reino dos fins" (terceira formulação) traz implícita a ideia de reciprocidade, e a formulação da lei universal (primeira), a ideia da universalidade, critérios amplamente adotados para caracterizar a justificação pública em teorias da justiça ${ }^{15}$.

Com Hegel avançamos nesse debate e aprendemos que o exercício da liberdade vai além de uma razão determinadora da vontade, ou da autolegislação da razão. Ela inclui o exercício da mediação social de vontades livres. Isso passa pelas instituições sociais. Neste sentido, a distinção entre moralidade e eticidade em muito contribui para a explicitação dos aspectos subjetivos e objetivos do exercício da liberdade. Ao explicitar o direito de moralidade, Hegel esclarece as condições da responsabilidade subjetiva, fundamentais na emissão de um juízo moral. Até aí vai Kant.

Ainda dentro do segundo capítulo da Filosofia do Direito, o direito de necessidade (Notrecht) é seguramente um dos componentes fundamentais do conteúdo da dignidade humana, até hoje. Hegel o desenvolve como um direito de moralidade, de forma que se tenha o direito de abrir uma exceção em caso de extrema necessidade. Ele visa a garantia de uma espécie de um "mínimo existencial", como forma de assegurar as condições mínimas

${ }^{13}$ Cf. SARLET, Ingo. Dignidade da pessoa humana e direitos fundamentais. Porto Alegre: Livraria do Advogado, 2002, p. 30.

${ }^{14}$ APEL, K. O. Teoria de la verdadad y ética del discurso. Barcelona: Paidós, 1995, p. 163.

${ }^{15}$ Cf. FORST, R. Contextos da Justiça. São Paulo: Boitempo, 2010, p. 52. 
de vida digna ${ }^{16}$. Embora reconheçamos a importância da autonomia para a dignidade, e isso devemos a Kant, temos de enfatizar que encontramos em Hegel outras dimensões do conteúdo da dignidade, notadamente com a distinção entre moralidade e eticidade e suas implicações para o reconhecimento recíproco. Com a eticidade Hegel evidencia o desdobramento objetivo da vontade livre nas instituições sociais, indispensável para se entender o âmbito da liberdade e, por conseguinte, o conteúdo da dignidade. Com a mediação social cai o apriorismo da moral kantiana e entra em cena o contexto e as circunstâncias.

Ainda no $\S 66$ da Filosofia do Direito, ao tratar da "inalienabilidade" do que chama de "determinações substanciais", Hegel chama a atenção para exemplos que caracterizam a "alienação da personalidade" retomados por sistemas éticos posteriores. A escravidão, a incapacidade de ter propriedade e a falta de liberdade sobre ela são os casos referidos. Da mesma forma, direitos fundamentais decorrem desse "direito de inalienabilidade da personalidade", atualmente assegurados pelas principais constituições democráticas, como o direito à integridade física e psíquica, o direito de propriedade, o direito de liberdade de consciência religiosa, bem como o direito de liberdade de expressão, dentre outros. Todo esse parágrafo é rico no esclarecimento do conteúdo próprio da dignidade humana, sobretudo ao referir os elementos constitutivos dos direitos de personalidade, amplamente referidos e assegurados pelas constituições democráticas mais bem-sucedidas.

\section{Hegel mais além de Kant: uma concepção ético- política de Constituição}

Com a fundamentação ética da Constituição, Hegel rompe com o contratualismo moderno e coloca as bases do comunitarismo. O Estado não é resultado de um contrato, tal como em Hobbes, Locke, Rousseau e Kant. Como ponto de partida temos uma concepção não-formal e não-normativa de Constituição ${ }^{17}$. Isso significa que existe uma formação política anterior e independente de sua formalização como Constituição. Dessa forma, todos as formações políticas têm uma Constituição, embora possa não ser escrita ${ }^{18}$. A base dessa Constituição é o "espírito do povo", composto pelos valores, costumes, a cultura e a história de um povo, como também a identidade ética. Em vista disso, indagar sobre quem deve fazer a Constituição seria

\footnotetext{
${ }^{16}$ Sobre o tema do mínimo existencial, ver WEBER, Thadeu. Ética e Filosofia do Direito. Petrópolis: Vozes, 2013, capítulo VI, p. 205. O direito de necessidade é objeto de estudo específico e consta de um artigo publicado na Revista Brasileira de Direitos Fundamentais \& Justiça. Belo Horizonte: ano 12, nº 39, 2018, p. 299.

${ }^{17}$ Cf. BOBBIO, N. Estudos sobre Hegel. São Paulo: Brasiliense, 1991, p. 91.

${ }^{18}$ Cf. BOBBIO, N. Estudos sobre Hegel. São Paulo: Brasiliense, 1991, p. 97.
} 
o mesmo que perguntar por quem deve fazer o espírito do povo. Ora, este já está sempre feito, embora possa sofrer alterações no transcurso do tempo. Isso significa que é um povo, enquanto "totalidade ética" e não um conjunto de indivíduos atomisticamente reunidos, que se deve reconhecer em sua Constituição enquanto categoria ético-política ${ }^{19}$. Mais precisamente, indagar sobre quem deve fazer uma Constituição pressupõe que já não exista nenhuma Constituição. Ora, já sempre existe uma formação política, pois "fazer" significa, nesse caso, "somente modificar" 20.

Diferente de Hegel, Kant defende uma concepção normativa de Constituição, isto é, a que assegura os direitos e liberdades a cada um através da lei. Trata-se de um Estado de Direito, de uma declaração de direitos, ou de um Estado limitado pelo Direito. O que lhe dá legitimidade é o pacto. Para Hegel, o que dá legitimidade à Constituição de um Estado é a sua adequação ao "espírito do povo" e este ao "espírito do tempo".

Com a fundamentação ética da Constituição, Hegel quer insistir na importância da consciência política de um povo, suas relações, costumes e tradições. É isso que lhe dá estabilidade. Por isso, afirma: “A Constituição de um determinado povo depende do modo e da cultura de sua autoconsciência. Nela reside a sua liberdade subjetiva e, por consequência, a realidade da Constituição" ${ }^{\prime 2}$. Não faz sentido, portanto, querer copiar uma Constituição de um outro povo. O "espírito" é outro.

Com essa fundamentação ética é perceptível que o Estado não é mais visto como um contrato social. Já nascemos num Estado e dentro de um determinado povo. Assumimos o ônus de tradições, costumes e leis, em parte, determinadas. Por isso, a Constituição "não é algo que meramente se faz: é trabalho de séculos, a ideia da consciência do racional, na medida em que se desenvolve num povo"22. Essa é a parte não-normativa e não-formal dela. O povo, de alguma forma, deverá poder identificar-se e reconhecer-se na sua Constituição, para que ela tenha eficácia. Ela não pode ser simplesmente criada por determinados sujeitos. Os espanhóis, escreve Hegel, recusaram a Constituição que Napoleão lhes dera, pois para eles, era algo "estranho". E continua: "Frente a sua Constituição, o povo deve ter o sentimento de que é seu direito e sua situação; caso contrário, pode existir exteriormente, mas não terá nenhum significado e valor" ${ }^{\prime 23}$.

\footnotetext{
${ }^{19}$ Cf. HEGEL, G.W.F. Grundlinien der Philosophie des Rechts. Frankfurt am Main: Suhrkamp, 1986b, §273, p. 439.

${ }^{20}$ HEGEL, G.W.F. Grundlinien der Philosophie des Recths. Frankfurt am Main: Suhrkamp, 1986b, §273, p. 439.

${ }^{21}$ HEGEL, G.W.F. Grundlinien der Philosophie des Recths. Frankfurt am Main: Suhrkamp, 1986b, § 274, p. 440.

${ }^{22}$ HEGEL, G.W.F. Grundlinien der Philosophie des Recths. Frankfurt am Main: Suhrkamp, 1986b, § 274, p. 440.

${ }^{23}$ HEGEL, G.W.F. Grundlinien der Philosophie des Recths. Frankfurt am Main: Suhrkamp, 1986b, § 274, p. 440.
} 
Evidencia, com isso, uma concepção ético-política de Constituição, longe do Contratualismo clássico.

Num primeiro momento, isso não poderia significar uma apologia ao nacionalismo? Certamente a concepção de Estado em Hegel indica a ideia de Estado/Nação. Mas, é preciso lembrar que acima ou além do espírito do povo está o "espírito do tempo", capaz de forçar a mudança do espírito de um povo. No dizer de Bobbio, o espírito do tempo "precede e de algum modo força a mudança do espírito do povo", sobretudo nos períodos de "aceleração histórica" 24 . A violação dos direitos humanos, por parte de um povo, seguramente não passa pela aprovação do espírito do tempo, uma vez que esse indica uma espécie de "Tribunal da História". Fundamenta-se em conquistas da história, já devidamente consolidadas. Isso quer dizer que uma boa Constituição, além de se identificar com o espírito do seu povo, é capaz de se adaptar gradualmente ao espírito do tempo. Esse tribunal a que o espírito do povo está sujeito é uma garantia de efetivação dos direitos humanos, também no nível internacional.

Mas será esse espírito do tempo capaz de evitar o nacionalismo?

O contexto histórico, hoje, é bem diferente do que era contemplado na primeira metade do século XX. As relações de interdependência comercial, cultual, industrial, econômica e política exercem pesada influência recíproca. O espírito do tempo compreende princípios universalíssimos que motivam a celebração de acordos internacionais visando o respeito aos direitos humanos e à soberania nacional. Esse mesmo espírito é constituído pelas conquistas da história. Está, portanto, também, em constante transformação. Retrocessos? Muito possivelmente não estamos livres disso, mas certas conquistas não têm volta, tais como: o respeito aos direitos humanos e a participação política de todos os cidadãos nos assuntos do Estado. Com isso, aprendemos muito com as duas guerras mundiais, por exemplo. $\mathrm{O}$ respeito à dignidade e aos direitos humanos passaram a ser elementos constitucionais essenciais.

Assim, vinculado diretamente ao espírito do tempo, o espírito do povo, como fundamento da Constituição, representa uma nova base de legitimação e justificação das relações políticas. Em última instância, não é o pacto que legitima o Estado, mas a sua formação política e a sua identidade ética. Não há dúvida de que, para obedecê-la, um povo precisa reconhecer-se na sua Constituição, escrita ou não.

No que se refere, pois, à relação entre ética e direito, os dois autores divergem. Hegel estabelece uma estreita vinculação entre eles, sobretudo na Filosofia do Direito, quando trata do "conceito do direito" (a ideia da liberdade) e suas formas de realização. Dentro disso o Estado é a efetivação da

${ }^{24}$ BOBBIO, N. Estudos sobre Hegel. São Paulo; Brasiliense, 1991, p. 108. 
substancialidade ética. Kant separa ética e direito, sobretudo na Doutrina do Direito, ao distinguir direito em sentido estrito e direito em sentido lato, e sustentar que o primeiro "não se mescla nada de ético" (dem nichts Ethisches beigemischt ist) ${ }^{25}$. Isso converge para a distinção, anteriormente feita, entre leis éticas e leis jurídicas e sua distinta base de motivação. $\mathrm{O}$ debate contemporâneo entre liberais e comunitaristas tem muito de suas origens nessa divergência entre Kant e Hegel.

Em termos de repercussão da filosofia política hegeliana podemos afirmar que, no contexto contemporâneo, a queda do Muro de Berlim e o fim da URSS são provas incontestáveis de que a história deu razão a Hegel e não a Marx. Se a esquerda hegeliana fracassou, será que com os últimos acontecimentos, tais como, a saída do Reino Unido da União Europeia, a própria eleição de Trump nos Estados Unidos e de Bolsonaro no Brasil, não indicam um certo retorno à direita hegeliana? A ideia do Estado $\mathrm{Na}$ cional não estaria voltando? (Inglaterra para os ingleses, América para os americanos, e talvez Brasil para os médicos brasileiros e não cubanos). A manutenção e o fortalecimento do espírito de um povo, sua identidade ética com suas origens, costumes e valores é o objetivo visado.

Ao que tudo indica, trata-se do espírito de um povo reencontrar-se na sua Constituição, enquanto ético-política e não só normativa, e pensá-la como adequada ao espírito do tempo. Este não haverá de permitir o nacionalismo, mas garantirá a unidade na diversidade, também nas relações internacionais. O espírito do tempo é constituído por princípios universalíssimos, endossáveis por todas as nações em garantir a realização de sua identidade ética. O grande desafio é, sem dúvida, encontrar formas adequadas de mediação entre o espírito de um povo e o espírito do tempo.

Essa é a grande contribuição de Hegel e sua relevância atual. As identidades éticas em suas diferenças estão asseguradas pelo contexto jurídico-político. Alguém poderia contra- argumentar dizendo que o mundo globalizado não comporta mais a ideia de Estado-Nação e de que, portanto, a ideia do Estado cosmopolita kantiano seria a mais adequada. De qualquer sorte, esse não deve ser entendido como um Estado Mundial, uma vez que não teríamos espaço suficiente para a diversidade. Kant propõe uma federação de Estados. Precisamos de organizações internacionais orientadas por princípios universalíssimos e endossáveis pelos povos, respeitada a sua diversidade. De Hegel, no entanto, aproveitamos a ideia do Estado estamental e de instituições fortes. Não se trata de um Estado de indivíduos particulares reunidos aleatoriamente, mas de indivíduos ordenados em estamentos e corporações. Se isso nivelar-se no mesmo padrão da sociedade civil e do Estado, também tem reflexos para as relações internacionais organizadas por instituições fortes, nos dias de hoje. Isso assegura a unidade na diversidade

${ }^{25}$ KANT, I. Die Metaphysik der Sitten. Frankfurt am Main: Suhrkamp, 1982, p. 339. 
e garante a estabilidade política. Os diferentes espíritos dos povos garantem a diversidade e o espírito do tempo resguarda a unidade. A ONU só será capaz de administrar os interesses e conflitos internacionais se for capaz de interpretar e orientar-se pelo "espírito do mundo", isto é, a partir de princípios universalíssimos acordados e endossáveis por todas as nações, e assim, torná-las efetivas. O respeito aos direitos humanos está entre eles.

\section{Honneth e os méritos da reatualização da Filosofia do Direito de Hegel.}

A releitura de Honneth, sobretudo da Filosofia do Direito de Hegel, dá um novo impulso ao interesse pela filosofia política. Consequentemente, temas como eticidade, mediação social, liberdade e reconhecimento recíproco adquirem novo significado e de notável atualidade.

Honneth aposta todos os argumentos no momento da eticidade hegeliana com o intuito de encontrar aí um terceiro modelo de liberdade ou realização individual capaz de ir além dos dois modelos incompletos apresentados nas duas primeiras partes da Filosofia do Direito e encontradas principalmente em Kant: a liberdade negativa e a liberdade optativa ${ }^{26}$. Em ambos os casos padecemos ainda de um "sofrimento de indeterminação". Esse é o ponto central da crítica ao formalismo da moral kantiana. Tanto num caso como no outro, permanecemos na fundamentação subjetiva da vontade livre e não passamos ao parâmetro das relações intersubjetivas e do reconhecimento recíproco. Ao chamar atenção para a insuficiência da liberdade negativa e da liberdade como autonomia, Honneth quer destacar as condições que a eticidade hegeliana deve cumprir para poder se libertar do "sofrimento de indeterminação", provocado por esses modelos incompletos de liberdade. Além de ter de oferecer "possibilidades de realização individual" e de "interação intersubjetiva" deve propiciar formas de "reconhecimento recíproco", ou seja, a liberdade como mediação social completa essa tarefa e realiza os objetivos da Filosofia do Direito.

O "sofrimento de indeterminação", provocado por esses dois modelos incompletos, recebe da eticidade uma "libertação", tanto dos aspectos que restringem a liberdade (os "comportamentos patológicos", as "dependências veladas"), quanto do livre arbítrio, ainda não mediados pelas instituições

\footnotetext{
${ }^{26}$ A liberdade negativa é entendida por Kant e por outros liberais como ausência de impedimentos; como autodeterminação individual capaz de excluir as inclinações ou determinações empíricas. A liberdade optativa refere-se à autodeterminação individual ou liberdade de escolha ou poder de tomar uma decisão. É uma espécie de causalidade por liberdade. É o poder de "representar o ato de autodeterminação incondicionalmente como uma escolha refletida entre inclinações ou impulsos da ação por sua vez indisponíveis". (Honneth, Sofrimento de Indeterminação, p. 58 e 59).
} 
sociais. O indivíduo se liberta da "subjetividade indeterminada", que trata apenas das formas mais imediatas da determinação da vontade livre, para entrar na "liberdade substancial" 27 . Esta se realiza na eticidade.

Honneth endossa o núcleo central da crítica hegeliana ao formalismo da moral de Kant. Trata-se da "objeção contra a cegueira em face do contexto" ${ }^{\prime 28}$. O problema está na abstração "do fato de que sempre nos movemos em um ambiente social no qual aspectos e pontos de vista morais já se encontram institucionalizados ${ }^{\prime 29}$. Kant, com isso, cairia numa indeterminação vazia. A razão descontextualizada teria que determinar a vontade, sem instâncias mediadoras. Ao reatualizar esse debate Kant/Hegel, quanto ao problema do contexto, Honneth explicita a base das controvérsias entre liberais e comunitaristas, que dominam os debates ético-políticos da segunda metade do século XX: os primeiros são "indiferentes ao contexto", os segundos "obcecados pelo contexto" ${ }^{30}$. Forst, em Contextos da Justiça, faz um mapeamento completo da discussão sobre esse assunto nas últimas décadas e apresenta a democracia deliberativa como uma alternativa às controvérsias entre liberais e comunitaristas.

A reatualização de Honneth tem sua ênfase maior no contexto da eticidade, exatamente porque esta representa o estágio da "libertação" das "patologias sociais" e a realização da liberdade individual nas mediações das instituições sociais e do reconhecimento recíproco. Em outras palavras, Honneth mostra quais são as condições mínimas que a eticidade deve satisfazer para que o indivíduo possa desvencilhar-se do "sofrimento de indeterminação", próprio dos modelos de liberdade que o antecederam.

A primeira condição refere-se à necessidade da eticidade colocar "à disposição possibilidades acessíveis de realização individual, de autorrealização" experienciáveis "por cada sujeito individual como realização prática de sua liberdade" ${ }^{\prime 31}$. Na família, mas principalmente nas corporações da sociedade civil, o indivíduo entra para realizar seus interesses particulares. Dessa forma, a efetivação desses está diretamente ligada "à condição da interação" Temos aqui, a segunda condição. A realização da liberdade individual, que se expressa nos mais variados interesses, requer a "interação intersubjetiva". A família e as corporações são exemplos de efetivação, mas também de limitação das liberdades individuais. Cumpre destacar que não existe liberdade sem mediação e reconhecimento recíproco. Eis a terceira condição.

Este é o papel da eticidade. Não se fala mais em liberdade natural, mas em liberdade mediada. Daí a importância da distinção entre livre arbítrio

\footnotetext{
${ }^{27}$ HONNETH, A. Sofrimento de Indeterminação. São Paulo: Esfera Pública, 2007, p. 99.

${ }^{28}$ HONNETH, A. Sofrimento de Indeterminação. São Paulo: Esfera Pública, 2007, p. 94.

${ }^{29}$ HONNETH, A. Sofrimento de Indeterminação. São Paulo: Esfera Pública, 2007, p. 95.

${ }^{30}$ FORST, R. Contextos da Justiça. São Paulo: Boitempo, 2010, p. 11.

${ }^{31}$ HONNETH, A. Sofrimento de Indeterminação. São Paulo: Esfera Pública, 2007, p. 106.

${ }^{32}$ HONNETH, A. Sofrimento de Indeterminação. São Paulo: Esfera Pública, 2007, p. 107.
} 
e liberdade. O livre arbítrio é expressão da vontade imediata e a liberdade é o livre arbítrio mediado e reconhecido. Essas mediações passam pelas instituições sociais. A eticidade é o nível da "segunda natureza". Sua função terapêutica consiste em oferecer as condições da libertação do "sofrimento de indeterminação", causado pelas formas imediatas de realização da vontade livre e que precisam de interação social, pois devem ser socialmente reconhecidas. As "ações intersubjetivas [...] exprimem formas determinadas de reconhecimento recíproco" ${ }^{33}$.

O grande mérito dessa ênfase honnethiana na eticidade é o destaque dado ao fortalecimento das instituições sociais. A família e as corporações, enquanto bases éticas do Estado, assumem um papel decisivo na realização, mas também na limitação das vontades livres. Além do mais, instituições fortes de mediação evitam o Estado totalitário. Com toda convicção, se o Estado vai mal, é porque a família e as corporações vão mal. As crianças não aprendem mais a mediar sua liberdade, ou seja, não sabem que a realização da liberdade também requer limitação. Ora, toda afirmação implica em negação. A eticidade é o espaço do reconhecimento recíproco e da intersubjetividade. $\mathrm{O}$ respeito às instituições confere objetividade e estabilidade aos princípios públicos de justiça, tais como o respeito aos direitos e liberdades fundamentais.

Digno de nota é o significado preciso de "reconhecimento" dado por Hegel na Enciclopédia e destacado por Honneth: o indivíduo é "digno" de reconhecimento quando "comporta-se para com os outros de uma maneira universalmente válida (allgemeingültige Weise benimmt), reconhecendo-os como ele mesmo quer valer - como livre, como pessoa" ${ }^{34}$. A ênfase está na reciprocidade. Um comportamento digno baseia-se em princípios e valores universalizáveis e, portanto, mutuamente reconhecidos. Por isso, a insistência nas mediações da eticidade.

O mérito dessa reatualização está na ênfase do fortalecimento das instituições sociais como formas de mediação e realização da liberdade individual. Isso começa com a família, passa pelas corporações da sociedade civil e se completa no Estado, na medida em que os indivíduos podem exercer uma "atividade universal" 35 . Os direitos fundamentais se concretizam no reconhecimento recíproco. Por isso, a liberdade mediada pelas instituições sociais e fortalecida por estas constitui a base das democracias contemporâneas. Com a concepção política e pública de justiça, Rawls entendeu a crítica de Hegel a Kant. De uma concepção formal de justiça partimos para uma concepção substantiva de justiça. Porém, essa só se vê concretizada

\footnotetext{
${ }^{33}$ HONNETH, A. Sofrimento de Indeterminação. São Paulo: Esfera Pública, 2007, p. 109.

${ }^{34}$ HEGEL, G.W.F. Enzyklopädie der Philosophischen Wissenschafften III. Frankfurt am Main: Suhrkamp, 1986a, § 432, Zusatz, p. 222.

${ }^{35}$ HEGEL, G.W.F. Grundlinien der Philosophie des Rechts. Franfurt am Main: Suhrkamp, 1986b, $\S 255$, p. 397.
} 
nas instituições sociais, enquanto instâncias mediadoras. É claro que estas não podem mais ser reduzidas aos três modelos propostos pela eticidade hegeliana: a família, as corporações e o Estado.

A leitura rawlsiana de Kant e honnethiana de Hegel trazem notáveis contribuições para a relevância desses dois continentes do pensamento filosófico moderno.

\section{Considerações finais}

Uma complementaridade entre Kant e Hegel pode ser facilmente estabelecida quando o assunto é a responsabilidade moral, ou melhor, a emissão de um juízo moral sobre a responsabilidade. Aspectos subjetivos e objetivos precisam ser distinguidos e considerados: propósitos e intenções, por um lado, meios, consequências e repercussões, por outro. Com a eticidade Hegel complementa Kant, na medida em que evidencia a necessidade de se avaliar o desdobramento objetivo da vontade livre nas instituições sociais. Não basta considerar a intenção do sujeito agente. É preciso levar em conta as repercussões e as consequências das ações humanas.

Autonomia e dignidade humana são temas que merecem dos dois filósofos alemães as mais convincentes formas de justificação e fundamentação. Impossível não recorrer a eles quando o assunto é a busca de princípios orientadores para as relações ético-políticas. O conteúdo da dignidade e da autonomia é expresso nas formulações do imperativo categórico, sobretudo a que trata do homem como fim em si mesmo e a que trata da autolegislação da razão. A Filosofia do Direito de Hegel amplia esse conteúdo com a explicitação da concretização da capacidade jurídica da pessoa do direito, na forma de direitos e liberdades fundamentais, tais como: o direito de propriedade, o direito de necessidade, o direito de moralidade, entre outros. Todo esse conteúdo é amplamente reconhecido pelas Constituições democráticas contemporâneas.

Com a fundamentação ética da Constituição, Hegel se desvincula de uma longa tradição do contratualismo moderno. Tem o grande mérito de ser um contraponto ou uma alternativa ao formalismo da filosofia moral e jurídica kantiana. Considerar os valores, os costumes e a história como a base não-formal da Constituição de um povo confere normatividade aos contextos e legitimidade às instituições. A polêmica em torno de um possível nacionalismo é enfraquecida e esclarecida com a explicitação da relação entre espírito do povo e espírito do tempo. Ficou demonstrado que uma boa Constituição, fundamentada no espírito de um povo, é aquela que se adapta gradual e constantemente ao espírito do tempo. Identificar ou construir os princípios ético-políticos que deveriam orientar os acordos nacionais e internacionais é o grande desafio do nosso século. 
Com Honneth, o tema do reconhecimento ganha nova interpretação e concede novo impulso ao interesse pela Filosofia do Direito de Hegel, notadamente, pela eticidade. Esta cumpre uma série de tarefas na libertação do "sofrimento de indeterminação" a que os modelos incompletos de liberdade estão sujeitos, fazendo do reconhecimento recíproco a condição de possibilidade da efetivação das liberdades individuais dentro das instituições sociais. Com as ideias de liberdade social, liberdade mediada e reconhecida, enfim, com a ideia de eticidade, Hegel efetivamente supera os modelos altamente dominantes na tradição da filosofia política, mormente em Kant. A liberdade negativa e a optativa (reflexiva) carecem da ideia de mediação e reconhecimento recíproco. Não existe liberdade em si ou indeterminada, mas mediada nas e pelas instituições sociais. A ideia de negação e limitação acompanha a ideia de concretização e determinação da vontade livre.

\section{Referências}

APEL, K. O. Teoria de la verdad y ética del discurso. Barcelona: Paidós, 1995.

BOBBIO, N. Estudos sobre Hegel: direito, sociedade civil, Estado. São Paulo: Brasiliense, 1991.

PATON, H.J. The Categorical Imperative: a study in Kant's moral philosophy. Philadelphia: University of Pennsylvania Press, 1971.

FORST, R. Contextos da Justiça. São Paulo: Boitempo editorial, 2010.

RAWLS, J. História da Filosofia Moral. São Paulo: Martins Fontes, 2005.

TUGENDHAT, E. Lições sobre ética. Petrópolis: Vozes, 1997.

KANT, I. Grundlegung zur Metaphysik der Sitten. Frankfurt am Main: Suhrkamp, 1974. Die Metaphysik der Sitten. Frankfurt am Main: Suhrkamp, 1982

HONNETH, A. Sofrimento de indeterminação: reatualização da Filosofia do Direito de Hegel. São Paulo: Esfera Pública, 2007.

HEGEL, G.W. F. Enzyklopädie der Philosophischen Wissenschafften III. Frankfurt am Main: Suhrkamp, 1986a.

1986b. . Grundlinien der Philosophie des Rechts. Frankfurt am Main: Suhrkamp,

SARLET, Ingo. (org). Dimensões da Dignidade. Porto Alegre: Livraria do Advogado, 2009.

. Dignidade da pessoa humana e direitos fundamentais na Constituição Federal de 1988. Porto Alegre: Livraria do Advogado: 2002.

WEBER, Thadeu. Ética e Filosofia do Direito: autonomia e dignidade da pessoa humana. Petrópolis: Vozes, 2013.

Endereço do Autor:

Rua Eça de Queiroz, 490/604

90670-020 Porto Alegre - RS

weberth@pucrs.br 